\title{
The Interdigital Brace and Other Grips for Termite Nest Perforation by Chimpanzees of the Goualougo Triangle, Republic of Congo
}

\author{
Julie J. Lesnik, ${ }^{1,2 \star}$ Crickette M. Sanz, ${ }^{3,4}$ and David B. Morgan ${ }^{4,5}$ \\ ${ }^{1}$ Department of Anthropology, Wayne State University, Detroit, MI 48202 \\ ${ }^{2}$ Department of Anthropology, University of Michigan, Ann Arbor, MI 48104 \\ ${ }^{3}$ Department of Anthropology, Washington University, Saint Louis, MI 63130 \\ ${ }^{4}$ Congo Program, Wildlife Conservation Society, Brazzaville, Republic of Congo \\ ${ }^{5}$ Lester E. Fisher Center for the Study and Conservation of Apes, Lincoln Park Zoo, Chicago, IL 60614
}

\begin{abstract}
KEY WORDS tool use; object manipulation; insectivory; entomophagy; Pan troglodytes; Macrotermes
\end{abstract}

\begin{abstract}
Studies of chimpanzee termite foraging enlighten our understanding of early hominin tool use not only by modeling the cognitive ability of our ancestors but also by emphasizing the possible role of social insects in the hominin diet. The chimpanzees of the Goualougo Triangle are known to have one of the largest and most complex tool repertoires reported for wild chimpanzees. One tool set habitually used by this population includes a perforating tool to penetrate the hard outer crust of elevated termite nests before fishing for termite prey with an herbaceous stem. Here, we report the variation present in the grips used on the perforating tool. Our analysis of video recordings of chimpanzee visitation to termite nests over a 3 -year period shows that these chimpanzees use a variety of grips to navi-
\end{abstract}

The cognitive skills behind chimpanzee tool use have been used to model early human ability, suggesting that early hominin tool industries, specifically the Oldowan, may be within the "adaptive grade" of chimpanzees (Wynn and McGrew, 1989; Wynn et al., 2011). However, extant great apes are unable to easily recreate Oldowanstyle tools using handheld percussion in experimental settings (Toth et al., 1993; Schick et al., 1999). It appears that cognitive understanding alone is not sufficient for tool production and that anatomy is also important in the evolution of human manual ability (Napier, 1956, 1960, 1962). In the most basic of comparisons, chimpanzees have relatively long fingers that are specialized for arboreal behavior and knuckle walking; however, it is the thumb in humans that is relatively long and promotes object manipulation (Napier, 1956, 1960; Preuschoft, 1973). The grips chimpanzees use to hold tools represent the compromise between manipulation and their locomotion (Napier, 1956, 1960) and create unique biomechanics of the hand that may even be reflected in the internal architecture of their metacarpals (Lazenby et al., 2011).

Napier defined two classes of grips, power and precision (Napier, 1956, 1960). In humans, the thumb is an essential part of both of these grips; however, chimpanzees can manage both power and precision tasks without any aid from the thumb. Chimpanzees' long proximal phalanges allow them to hook narrow, slender objects under their fingers and to produce a power grip that gate the challenges encountered in opening a termite nest. For situations in which the soil is most hardened, perforating requires force and a power grip is often used. When the soil in the passageway is loose, precision grips are suitable for the task. One of the preferred grips reported here is an interdigital brace, which has previously been described in studies of how some people hold a pencil. In this study, for the first time, the interdigital brace has been thoroughly described for chimpanzees. The various strategies and grips used during perforation emphasize the importance of termites as a nutritional resource that should be considered more strongly as a food used by early hominins. Am J Phys Anthropol 157:252-259, 2015. @ 2015 Wiley Periodicals, Inc.

needs neither thumb nor palm (Napier, 1960). Although humans show a strong preference for using the distal ends of the fingers, especially the pads, against the thumb in precision grips, chimpanzees are more varied, using additional grips such as tip of the thumb to tip of the index finger and a no-thumb scissor grip between two adjacent fingers for delicate tasks (Napier, 1960; Christel, 1993).

Scholars have noted that the categories created by Napier are limiting given the wide range of

\footnotetext{
Additional Supporting Information may be found in the online version of this article.

Grant sponsor: Helen McKaig Spuhler Memorial Graduate Research Grant, Department of Anthropology, University of Michigan; Grant sponsor: National Geographic Society; Columbus Zoo.

*Correspondence to: Julie Lesnik, Department of Anthropology, Wayne State University, 656 West Kirby Street, 3054 Faculty Administration Building, Detroit, MI 48202, USA.

E-mail: julie.lesnik@wayne.edu
}

Received 1 October 2013; accepted 13 January 2015

DOI: 10.1002/ajpa.22706

Published online 28 April 2015 in Wiley Online Library

(wileyonlinelibrary.com). 
manipulative behaviors both humans and nonhuman primates accomplish. Napier's power and precision categories are still used in a general sense for the patterns of movements they represent (Marzke et al., 2009); however, more attention is now given to specific grips used for different activities. Some of the most comprehensive of these studies include Christel's (1993) research across hominoids of grasping behavior for small, desirable foods such as seeds or raisins; Marzke and Wullstein's (1996) report of the grips used for a range of activities, including feeding behaviors and object manipulation, conducted with a large sample of chimpanzees; and Boesch and Boesch's (1993) descriptions of chimpanzee hand grips in nut-cracking tool use in the wild. With regard to chimpanzee tool use for termite foraging, chimpanzees are well documented to hold fishing probes with the padto-side precision grip (Goodall, 1970; McGrew et al., 1979). Our study marks for the first time that grips have been specifically identified for termite nest perforation, which involves using the tip of a rigid twig tool to open the crust of an elevated termite nest (Sanz et al., 2004).

Chimpanzees manage a range of precision grips despite potential hindrances in their hand morphology, although they differ from human grips in notable ways. In picking up small items (e.g., a raisin), chimpanzees as well as most apes often use tip of the thumb to tip of the index finger, whereas humans prefer the use of the volar pads on these digits (Christel, 1993). Chimpanzees' second preferred precision grip for this task is tip of the thumb to the radial aspect of the proximal joint of the index finger. Although humans use pad-to-side grips for other tasks such as holding and turning keys, they were not seen to use these types of grips to pick up small objects (Christel, 1993). The pad-to-side grips are common across apes, likely due to a low thumb-forefinger index as well as short digital flexor tendons that do not facilitate extension of the distal interphalageal joint during padto-pad opposition (Tuttle, 1969a; Christel, 1993). Additionally, when analyses are extended beyond hominoids into the rest of Anthropoidea, these other primates are found to be highly dexterous and capable of precision grasping, especially those living in more terrestrial habitats (Pouydebat et al., 2008; Meulman et al., 2012).

Power grips have been thought to come more naturally to chimpanzees as they can modify suspensory postures to be used on other objects. For instance, the hook grip, which is a classic Napier power grip, is used to swing below branches; however, with little modification, it can hold cylindrical objects for hammering activities (Marzke and Wullstein, 1996). For nut-cracking activities in the wild, chimpanzees use a stone or club hammer with a power grip, maintaining tool contact with palm, thumb, and fingers (Boesch and Boesch, 1993). If the size of the hammer is too small, the chimpanzees risk hitting their fingers on the anvil or the nut. The chimpanzees of the Taï Forest in Côte d'Ivoire have been observed to modify this power grip on smaller hammers so as to avoid injuring their hands (Boesh and Boesch, 1993). These modifications include stretching out the fourth and fifth fingers to remove them from harmmer's way while maintaining a type of power grip with the palm, thumb, and second and third fingers, as well as the opposite, where the second and third fingers are removed from the grip, and the thumb and palm work with the fourth and fifth fingers to grip the hammer (Boesch and Boesch, 1993).

The grips used by chimpanzees were previously thought to be quite static where objects are held but are not translated or rotated (Christel, 1993; Marzke and Wullstein, 1996). However, more recent studies have shown that both chimpanzees and gorillas are capable of complex intramanual object translation, where the digits are used to move objects within one hand, suggesting that this ability is not a unique human trait and likely present in the last common ancestor (Byrne and Corp, 2001; Corp and Byrne, 2002; Crast et al., 2009). These manual skills suggest that this level of neuromotor control evolved in the distant past and has been maintained by the nonhuman African apes during the evolution of specialized knuckle-walking morphology, as well as elaborated over the course of human evolution (Tuttle, 1969b; Pouydebat et al., 2008; Lovejoy et al., 2009; Almécija et al., 2010).

Chimpanzee grips can be studied to investigate the problem-solving techniques used by these apes to complete a task for which their hands may not be best suited. The chimpanzees of the Goualougo Triangle, Republic of Congo, provide an ideal study population for such questions as they are known to have one of the largest and most complex tool repertoires reported for wild populations of chimpanzees (Sanz and Morgan, 2007). Additionally, the remote video archives (Sanz et al., 2004) provide the ability to re-watch, stop-frame, and slow-motion the actions of the chimpanzees, allowing for more accurate observations of tool manipulation.

Termite fishing is one of the tool-use activities conducted by the Goualougo chimpanzees. Termites have tunnels to exit their nests to forage, but they immediately reseal these exit/entry tunnels after use. Soil must often be removed from these tunnels before an herbaceous stem can be inserted for termite fishing. Sometimes, this soil can be removed manually; however, some members of the chimpanzee population residing in the Goualougo Triangle have been observed to use a twig to open the crust of elevated termite nests. This "perforation twig" is the first tool of a set, where first the perforation twig is used to open the sealed tunnels near the surface of an elevated termite nest (typically Macrotermes muelleri) so that a second tool, the herbaceous fishing probe, can be inserted into the nest to extract termites (Fig. 1). Chimpanzees fashion tools for perforation from rigid twigs usually found within arm's reach of the termite nest. These twigs are quite variable in length $(32.9 \pm 19.4 \mathrm{~cm}$, range: $5-91 \mathrm{~cm}, n=54)$ but are rather consistent in diameter $(5.9 \pm 1.4 \mathrm{~mm}$, range: 3 $9 \mathrm{~mm}, n=54$ ) (Sanz and Morgan, 2007). Although opening the termite exit tunnels near the surface of an elevated termite nest requires clearing a soil blockage of less than $1 \mathrm{~cm}$, the toughness of the cemented structure of the nest is variable and perforation is not always successful (Sanz et al., 2004).

Here, we investigate the grip preferences of chimpanzees in the Goualougo Triangle population during termite nest perforation. Some of the grips used for perforation fit into the classic power and precision categories; however, the most notable is an interdigital brace that cannot be easily categorized into one of these groups.

\section{MATERIALS AND METHODS}

The Goualougo Triangle is located in the southern portion of the Nouabalé-Ndoki National Park, which is in 


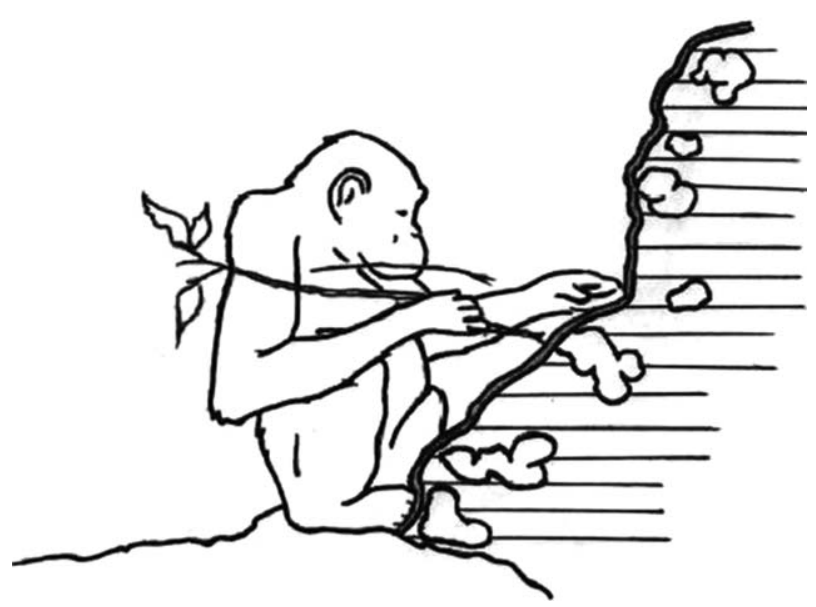

Fig. 1. An adult female using a perforating twig to open termite exit holes on the surface of a termite nest. She holds a brush-tip fishing probe in her mouth. In addition, note the outer protective wall and peripheral chambers within the termite nest (Macrotermes muelleri). From Sanz et al., 2004.

the northern Republic of Congo. This study area encompasses evergreen and semideciduous lowland forest, with altitudes ranging between 330 and $600 \mathrm{~m}$. The study site is home to several communities of chimpanzees. The Moto community is the main study group and was composed of 70 individuals at the time of this study. The climate is transitional between the Congo-equatorial and subequatorial climatic zones. Rainfall is bimodal, with a main rainy season from August through November and a short rainy season in May.

Remote video cameras were used for surveillance of 10 termite nests across three communities between 2003 and 2007. If animal movement is detected by the passive infrared sensor, the camera records for $2 \mathrm{~min}$ and continues until motion is no longer detected. Each month of the year is represented in the videos collected.

Each recording was scored for age-sex class of chimpanzees, individual identification, and tool use. Tapes that include perforation were further scored for the specific grip used to manipulate the perforating tool (e.g., pad-to-side and hook). A series of perforation is defined as the time between starting and stopping perforation. In this time, the chimpanzees may pause and resume perforating, switch grips, switch hands, switch holes, or switch locations on the nest. A bout of perforation is defined as the distinct period of tool use within a perforation series. The end of a bout is defined by switching grips, switching hands, switching holes, switching location, terminating perforation altogether, or successfully fishing for prey. A total of 147 series of perforation were viewed and coded for a minimum of 13 chimpanzees yielding 290 bouts, 157 of which yielded unobstructed views of the hand where the grip could be identified and recorded.

The observed grips were ranked in the order of relative power. The dichotomous definitions of power and precision are not sufficient for understanding the range of grips available to chimpanzees for this task; however, the variable crust toughness of termite nests requires differential amounts of power and/or precision in the grips at different times. By ranking the grips in relative power, we are able to use switches in grips as an indicator of the manipulative needs during different phases of a perforation series. Power estimates were established
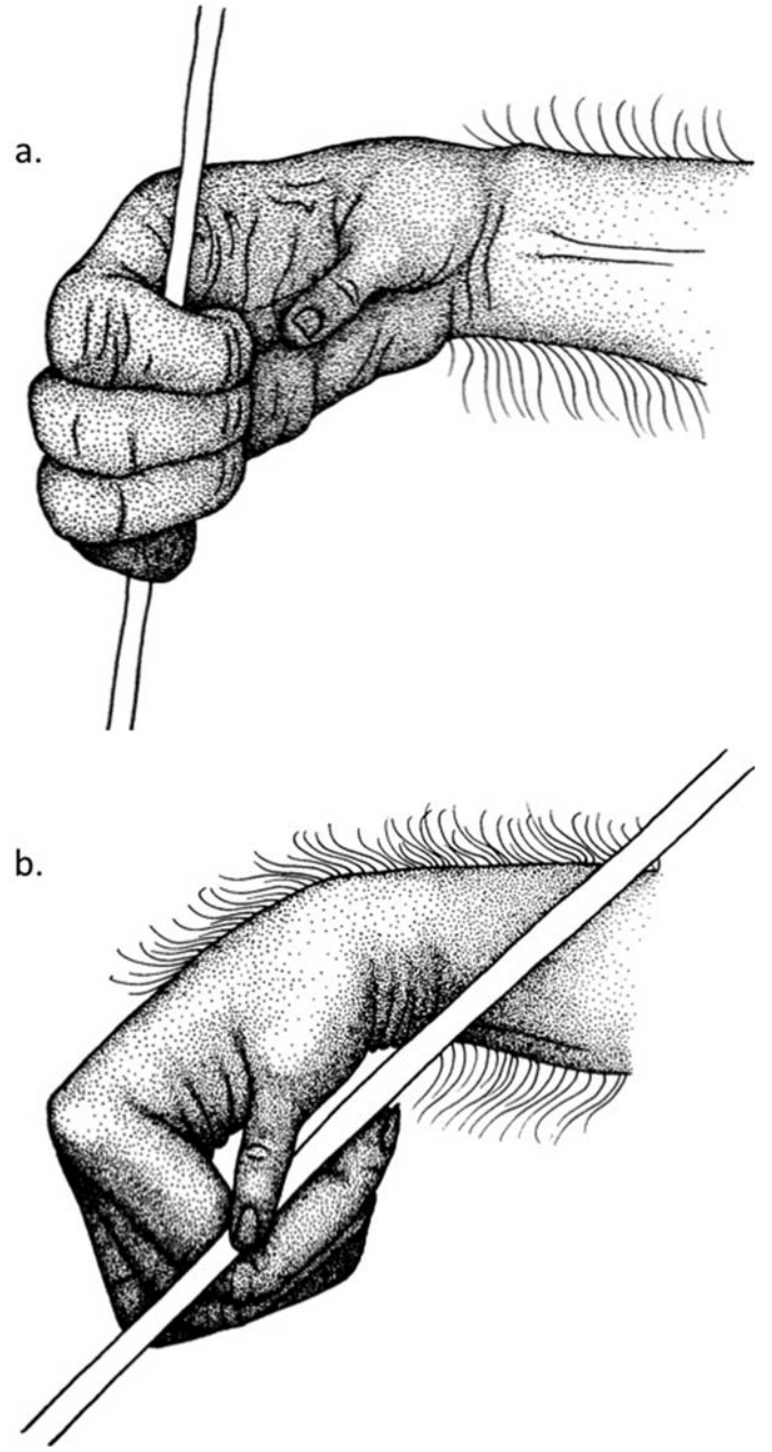

Fig. 2. (a) Chimpanzee hand using a power grip known as the hook grip. All four fingers wrap around the tool and lock it into place. (b) Chimpanzee hand using a precision grip known as the pad-to-side grip. This grip is common on herbaceous termite fishing stems and occasionally used by Goualougo chimpanzees on perforating twigs.

roughly on how many digits, and thus muscles, are incorporated when the grip is strengthened. For example, a hook grip incorporating the four fingers is more powerful than a pad-to-side grip that relies almost exclusively on the thumb. Intermediate to these grips are the interdigital braces that incorporate three digits. These grips are described below.

\section{RESULTS}

Seven specific grips were recorded as follows:

- Hook grip: A classic Napier power grip. The tool is enclosed by four flexed fingers (Fig. 2).

- Both-hands grip: The addition of a second closed hand on top of or next to the first hand, sometimes obscuring the more specific placement of the tool through the first hand. The two hands work together and are 

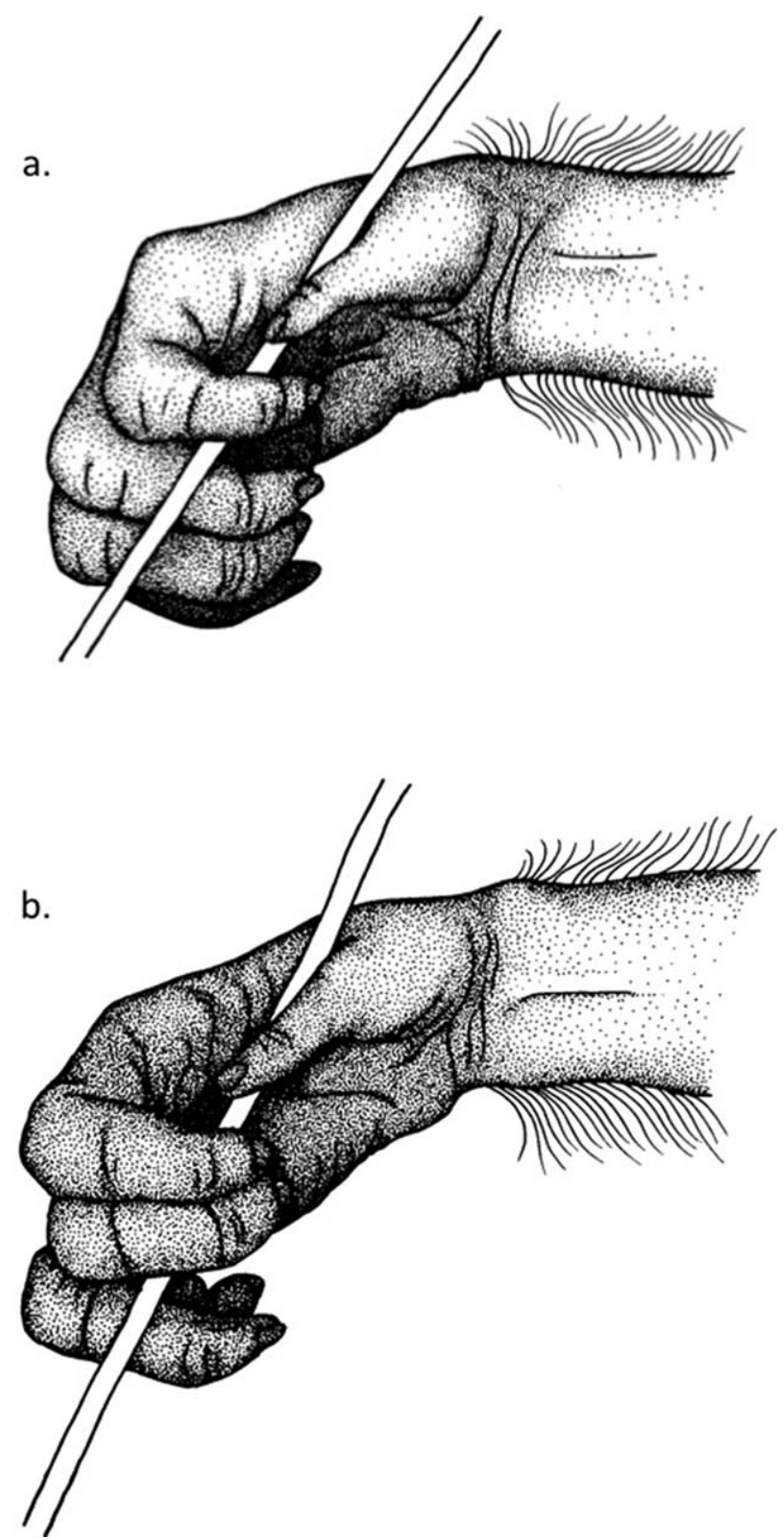

Fig. 3. Chimpanzee hands using intermediate grips known as interdigital braces. (a) Interdigital 2/3 brace where the tool exits between the second and third digits "bracing" in the webbing of the thumb and weaving under the index finger. This grip is used by Goualougo chimpanzees on perforating twigs. (b) Interdigital $3 / 4$ brace where the tools exits between the third and fourth digits after "bracing" in the webbing of the thumb and weaving under the first two fingers. This is the most common interdigital brace used by the Goualougo chimpanzees.

considered here to create the most powerful grip that can resist the most force.

- Pad-to-side grip: A classic Napier precision grip. The tool is pinched between the pad of the thumb and the side of the index finger (Fig. 2).

- Interdigital 2/3 brace: The tool exits the hand between the proximal or middle phalanges of the second and third digits after "bracing" in the webbing of the thumb and weaving under the index finger (Fig. 3).
TABLE 1. Individual grips observed in the Goualougo chimpanzees

\begin{tabular}{|c|c|c|c|}
\hline Grip & $\begin{array}{l}\text { Power } \\
\text { ranking }\end{array}$ & $\begin{array}{l}\text { Number of } \\
\text { individuals } \\
\text { exhibiting } \\
\text { this grip }\end{array}$ & $\begin{array}{c}\text { Number of grip } \\
\text { observations }\end{array}$ \\
\hline Both hands & 1 & 10 & $n=54 ; 34 \%$ \\
\hline Hook & 2 & 8 & $n=31 ; 20 \%$ \\
\hline Interdigital $2 / 3$ & 3 & 6 & $n=12 ; 8 \%$ \\
\hline Interdigital $3 / 4$ & 3 & 6 & $n=37 ; 24 \%$ \\
\hline Interdigital $4 / 5$ & 3 & 1 & $n=2 ; 1 \%$ \\
\hline Pad-to-side & 4 & 5 & $n=21 ; 13 \%$ \\
\hline
\end{tabular}

Columns show relative power of the grip, the number of individuals recorded using the grip, and the number and percent of times the grip was recorded for all observed bouts. The threepod grip was intentionally left out of this table as its one occurrence was recorded for a juvenile.

- Interdigital $3 / 4$ brace: The tool exits the hand between the proximal or middle phalanges of the third and fourth digits after "bracing" in the webbing of the thumb and weaving under the first two fingers. This is the most common interdigital brace (Fig. 3 and Supporting Information Video S1).

- Interdigital 4/5 brace: The tool exits the hand between the proximal or middle phalanges of the fourth and fifth digits after "bracing" in the webbing of the thumb and weaving under the first three fingers. This grip was only observed two times by the same individual.

- Three-pod grip: The addition of a foot to the twohanded grip, which was observed only once for a juvenile chimpanzee.

The most powerful grip, ranked 1, is the both-hands grip (Table 1). Although chimpanzees are known to use an open hand to guide a tool they are controlling with their predominant hand, the both-hands grip here is defined as both hands closed around the tool and working together. This grip is regularly observed with a corresponding thrust of the upper body against the tool. The least powerful grip, ranked 4, is the pad-to-side grip, which is one of Napier's classic precision grips. Within this range are the hook grip, ranked 2, a classic Napier power grip, and the three different interdigital braces, all ranked 3 .

The interdigital braces were given an intermediate power ranking based on the definition of number of digits used in the grip. Most simply defined, the grips use three digits: the thumb and the two fingers between which the tool passes. It is important to note that the force through the tool may not be generated exclusively from the hand. When the soil in the exit tunnel is compact, the chimpanzees often brace the weight of their upper bodies against the tool; this is most exaggerated with the two hands grip, but is generally true with any tough perforation bout. However, this bracing can only be effective if the grip on the tool is strong enough to maintain stability, thus why it is seen most often with the two-hand grip. Regarding the other grips, a tool being held with a pad-to-side precision grip would slip through the hand in such an instance, while a hook grip would be more effective as the tool is thoroughly enclosed. With the interdigital brace, the stability of the tool is dependent on the position of the hand relative to the force being put through the tool. With instances 
TABLE 2. Most frequent perforating chimpanzees

\begin{tabular}{llcccc}
\hline Individuals & Age-sex class & Number of grips & Number of bouts & Contribution to total (\%) & Number of grip switches \\
\hline Theresa & Adult female & 5 & 40 & 25 & 11 \\
Talangai & Adult male & 4 & 21 & 13 & 6 \\
Maya & Adult female & 2 & 19 & 7 & 1 \\
Vanessa & Adult female & 3 & 11 & 6 & 3 \\
Sarah $^{\mathrm{a}}$ & Adult female & 3 & 10 & 6 & 1 \\
Samantha $^{\mathrm{a}}$ & Juvenile female & 3 & 10 & 29 & 1 \\
Other & - & 6 & 46 & & 8 \\
\hline
\end{tabular}

Columns show the individual's age and sex classification, the number of different grips used by that individual, the number of bouts recorded with visible grips for that individual, the percentage of total bouts recorded that were of that individual (percent from 157 total observed bouts), and the number of times that individual was observed switching grips. The "Other" category is for individuals who could not be identified because of their location relative to the camera.

${ }^{a}$ Mother-daughter relationship.

TABLE 3. Chimpanzee grip switches

\begin{tabular}{llc}
\hline First grip & Grip switched to & $\begin{array}{c}\text { Number of } \\
\text { of times }\end{array}$ \\
\hline Hook $(n=31)^{\mathrm{a}}$ & Interdigital 3/4 & 3 \\
& Interdigital 2/3 & 2 \\
& Both hands & 1 \\
Both hands $(n=54)$ & Unknown & 1 \\
& Pad-to-side & 3 \\
& Interdigital 2/3 & 1 \\
& Interdigital 3/4 & 3 \\
& Interdigital 4/5 & 1 \\
Pad-to-side $(n=21)^{\mathrm{b}}$ & Hook & 1 \\
& Both hands & 2 \\
Interdigital $2 / 3(n=12)$ & Unknown & 3 \\
Interdigital $3 / 4(n=37)$ & Hook & 1 \\
Interdigital $4 / 5(n=2)$ & Both hands & 1 \\
Unknown & Both hands & 1 \\
& Both hands & 1 \\
& Hook & 1 \\
\hline
\end{tabular}

The chimpanzees were seen switching grips a total of 31 times (20\% of the total 157 bouts). These switches were significantly more common toward a grip less powerful than the starting grip ( $z$-test $P<0.01)$. Of 28 switches, $23(82 \%)$ were to a less powerful grip, and five (17\%) were toward a more powerful grip.

${ }^{a}$ The number of times a grip was switched away from a hook grip is significantly more than the number of times grips were switched away from the three interdigital braces combined [seven of 31 times $(22 \%)$ vs. three of 51 times (6\%), $z$-test $P<0.05]$.

${ }^{\mathrm{b}}$ The number of times a grip was switched away from the padto-side grip is more than the number of times grips were switched away from the three interdigital braces combined [four of 21 times $(19 \%)$ vs. three of 51 times (6\%), although not significant to 0.05].

where perforation maneuver is perpendicular to the nest, it is likely that the tool will push through the hand, similar to what is expected with the pad-to-side grip. However, there are other instances where the perforation motion is downward as well as inward against the nest, and it is here that the tool can resist great force as it is braced between the fingers positioned superior to the tool and the webbing of the thumb at the inferior. Unfortunately, at this time, empirical data on body posture have not been collected because it is difficult to standardize the measurements across the videos; however, the angles appear to be highly variable.

The most common grip used by the Goualougo chimpanzees for termite nest perforation was the use of both hands (Table 1). Individual chimpanzees had an average of three different grips in their repertoire for this task (Table 2), and the chimpanzees were seen switching from one grip to another before successful perforation $20 \%$ of the times (31 of the total 157 times; Table 3). Two-proportioned $z$-tests show significance in the preference to switch to a less powerful grip and the preference to maintain use of interdigital braces (Table 3).

\section{DISCUSSION}

The variability in grips used by the chimpanzees of the Goualougo Triangle to perforate termite nests demonstrates not only their manipulative abilities but also their finesse in addressing the task's challenges. Perforation appears to have two phases, a first that requires force to push through the blockage created by the termites and a second that requires more manipulation for clearing the loosened soil out of the passageway. The distinction between these two phases is most noticeable when chimpanzees switch their grips; however, a single grip can complete the progression, especially in instances where the nest is not maximally resistant. In the cases where there are no switches in grips, the first phase of perforation is most easily identified by the chimpanzee's upper body thrusting against the tool. The second phase of perforation is identified by a more relaxed upper body posture and distinctive "wiggling" of the tool hand clearing the loosened soil (Supporting Information Video S2).

Sabater Pi (1974) noted that chimpanzees using a stick to probe into an anthill used a grip where the hand was closed with the thumb facing upward. This grip fits the description of a hook grip, a classic Napier power grip, and we observe that it is a common grip used on perforation twigs. The Goualougo chimpanzees are also seen using the pad-to-side grip on perforation twigs, a classic Napier precision grip most common for termite fishing with herbaceous stems. However, most notable is the use of intermediate grips to these categories. Interdigital braces are almost equally as common as the hook grip for perforating.

The interdigital braces are ranked less powerful than the hook grip but more powerful than the pad-to-side grip. In a power grip such as the hook grip, closing the whole hand increases the grip's strength, whereas in a precision grip such as a pad-to-side grip, this is accomplished by pressing together two digits. With the interdigital brace, it is the bracing of the tool against the hand that gives the grip its greatest strength.

"Interdigital brace" is a definition used by child development specialists to describe a variant of pencil grip (Selin, 2003). Handwriting is a precise action that 


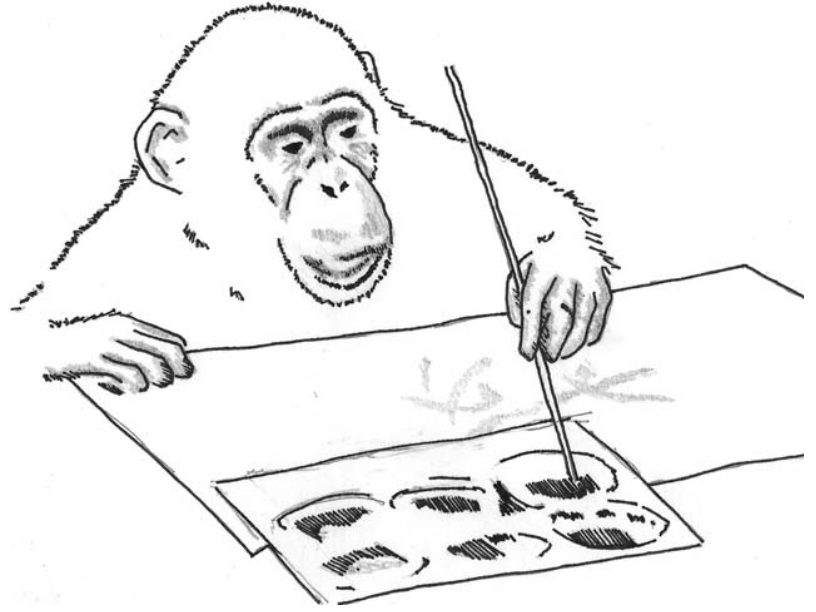

Fig. 4. This drawing was modeled after a photo of "Congo" holding a paintbrush (Morris, 1963). What Morris described as an "advanced human-style grip" is described here as an interdigital $2 / 3$ brace, where the tool exits the hand between the index and middle finger after "bracing" in the webbing of the thumb and weaving under the index finger.

requires an appropriate grip, and the relatively long human thumb gives us the strength necessary to apply pencil to paper. When the interdigital brace is used to hold a pencil, it is considered "inefficient" by specialists because the unnecessary power behind it can lead to hand fatigue. When chimpanzees use this grip, it is likely the closest their hand can get to any of the traditional human pencil grips. Morris (1963) described the use of this grip by the chimpanzee "Congo" holding a paintbrush as an "advanced human-style grip" (Fig. 4). In the Goualougo Triangle, it is used by half of the different chimpanzees observed perforating termite nests. Furthermore, chimpanzees rarely switch away from the grip once used, switching only three of the 51 times it was observed, suggesting it is effective for their purposes.

The most common switch between grips is away from the both-hands grip, a simple modification that dramatically changes the amount of force the chimpanzee is placing on the tool. In the both-hands grip, there is a predominant hand and an aid hand. The specific grip of the predominant hand on the tool is usually obscured by the addition of aid hand over top. When the chimpanzees switch away from the both-hands grip, they remove the aid hand, and the grip of the predominant hand, now labeled as a new grip, can usually be observed. It can be seen in Table 3 that the chimpanzees switch away from the both-hands grip to each of the grips documented in this study (with the exception of the threepod grip), including a different variation of the bothhands grip where predominant and aid hands were switched. These results suggest that the chimpanzees do not have a clear pattern for which grips require the addition of an aid hand.

The initial iteration of this research predicted that the chimpanzees would switch to more powerful grips when the termite nest surface was found to be too tough (Lesnik, 2011a). However, we demonstrate here that the chimpanzees begin their activities prepared for the tough crust, often gripping the tool with both hands to start, and switch to one-handed grips to clear away loosened soil after successful perforation (Supporting
Information Video S2). The minimal switching that occurs when an interdigital brace is being used suggests that the chimpanzees are able to accomplish both portions of the perforation task, the breach and the soil clearing, with this grip. With regard to Napier's categories, these results led us to think of the interdigital braces as intermediate, using ample power while maintaining the ability to perform more precise maneuvers.

There was one documented instance of the three-pod grip, which is essentially the both-hands grip accompanied by a foot, similar to how a gardener steps on a spade. This grip is notable because it is commonly used by the Goualougo chimpanzees for another termite foraging activity where they gain access to subterranean termite nests (typically Macrotermes lilljeborgi) by puncturing through the ground to create a tunnel into an underground chamber. This task requires a much more robust tool, and the chimpanzees in the Goualougo Triangle are in turn more selective in choosing material for these tools. The chimpanzees are seen to make nearly all their puncturing tools from Thomandersia hensii, which is straight and rigid with uniform diameter (Sanz and Morgan, 2007). The three-pod grip for elevated nest perforation was used by a juvenile chimpanzee that clearly had not refined her tool-using techniques.

Although many populations of chimpanzees use tools to forage for termites, the Goualougo chimpanzees are one of the few that use tool sets. Additionally, not every individual in the Goualougo Triangle who forages for termites uses perforation twigs; some individuals fish for termites through available open tunnels only. Although the specific focus of this study was to understand the grips and technique used by these chimpanzees, it also serves to build our understanding of demographic patterns of this behavior. At this point, it remains unknown if variation in preferences for grips reflects differences in observational learning or individuality in implementation. As longitudinal studies continue at the site, we can learn more about how this behavior is acquired across the generations of this population.

The intricate process the Goualougo chimpanzees use to forage for termites is additional evidence that they possess cognitive processes capable of producing simple tool industries, which may be informative about the capabilities of the last common ancestor and the earliest hominins. Anthropologists regularly reconstruct hominin manipulative and cognitive abilities based on chimpanzee models; however, they rarely discuss how hominins could have benefited from using the perishable tools chimpanzees regularly use. Paleoanthropologists seem to exercise great caution to not name something a tool without ample evidence. This pattern likely traces back to the refutation of the osteodontokeratic culture. Dart (1975) proposed that fragmented bones, tooth rows, and horn cores were the artifacts of a predatory hominin culture; however, this was later shown by Brain (1967) to be the remnants of natural taphonomic processes. In the case of termite foraging, however, it is a complex task maintained in several populations of chimpanzees (Sanz et al., 2014), suggesting that this behavior must be advantageous to the participating individuals. Populations of people today across the world eat termites, as do other genera of great apes (Bodenheimer, 1951; Tutin and Fernandez, 1983; Galdikas, 1988). Depending on the specific termites being consumed, they can be a significant source of protein, fat, 
or micronutrients (Deblauwe and Janssens, 2008; Lesnik, 2014). This evidence alone should argue for termite foraging in the last common ancestor, even if it was accomplished without the aid of tools. Fortunately, we do have bone artifacts from Lower Paleolithic sites in South Africa that preserve wear patterns consistent with tool use and with hypotheses related to digging into termite nests (Backwell and d'Errico, 2001; d'Errico and Backwell, 2009) and even termite nest perforation (Lesnik, 2011b). These bone tools have opened up the conversation of termites in the hominin diet. The earliest hominins could have benefited by supplementing their diets with termites in ways similar to chimpanzees, and larger brained hominins could minimally modify prey choice and rate of acquisition to increase dietary quality (Lesnik, 2014). For this reason, the role of insects in the diet and the possible use of perishable tools, maybe even tool kits like the ones seen at the Goualougo Triangle, should not be overlooked for our early ancestors.

\section{CONCLUSION}

Chimpanzees exhibit a high degree of flexibility in object manipulation. The chimpanzees of the Goualougo Triangle take advantage of several different grips while conducting termite nest perforation, a task that is variable in its manual requirements. An interdigital brace appears to be intermediate in the power and precision it affords when using a tool and is one of the preferred ways chimpanzees navigate this complicated task. The intricate process the Goualougo chimpanzees use to forage for termites is additional evidence for the importance of this activity and suggests that insects as a food resource should not be overlooked for our hominin ancestors.

\section{ACKNOWLEDGMENTS}

The authors thank the opportunity provided to work in the Nouabalé-Ndoki National Park and especially the Goualougo Triangle. This work would not be possible without the continued support of the Ministère de l'Economie Forestière et du Développement Durable (République du Congo), the Ministère de la Recherche Scientifique (République du Congo), and the Wildlife Conservation Society's Congo Program. The authors thank Stephanie Musgrave for her helpful comments on an earlier version of this manuscript. The authors also thank Alessandra Kelley who illustrated Figures 2 and 3. Figures 1 and 4 were drawn by David Morgan. Finally, the authors thank the editors at AJPA and two anonymous reviewers for their detailed and thoughtful comments.

\section{LITERATURE CITED}

Almécija S, Moyà-Solà S, Alba DM. 2010. Early origin for human-like precision grasping: a comparative study of pollical distal phalanges in fossil hominins. PLoS One 5: e11727.

Backwell LR, d'Errico F. 2001. Evidence of termite foraging by Swartkrans early hominids. Proc Natl Acad Sci USA 98: 1358-1363.

Bodenheimer FS. 1951. Insects as human food. The Hague: Junk.

Boesch C, Boesch H. 1993. Different hand postures for pounding nuts with natural hammers by wild chimpanzees. In: Prueschoft and Chivers, editors. Hands of Primates. New York: Springer-Verlag. p 31-44.

Brain CK. 1967. Bone weathering and the problem of bone pseudo-tools. S Afr J Sci 63:97-99.
Byrne R, Corp N. 2001. Manual dexterity in the gorilla: bimanual and digit role differentiation in a natural task. Anim Cogn 4:347-361.

Christel M. 1993. Grasping techniques and hand preferences in Hominoidea. In: Prueschoft and Chivers, editors. Hands of primates. New York: Springer-Verlag. p 91-108.

Corp N, Byrne R. 2002. The ontogeny of manual skill in wild chimpanzees: evidence from feeding on the fruit of Saba florida. Behaviour 139:137-168.

Crast J, Fragaszy D, Hayashi M, Matsuzawa T. 2009. Dynamic in-hand movements in adult and young juvenile chimpanzees (Pan troglodytes). Am J Phys Anthropol 138:274-285.

Dart R. 1957. The osteodontokeratic culture of Australopithecus prometheus. Pretoria: Transvaal Museum.

Deblauwe I, Janssens G. 2008. New insights in prey choice by chimpanzee and gorillas in Southeast Cameroon: the role of nutritional value. Am J Phys Anthropol 135:42-55.

d'Errico F, Backwell LR. 2009. Assessing the function of early hominin bone tools. Am J Archaeol Sci 36:1764-1773.

Galdikas BMF. 1988. Orangutan diet, range and activity at Tanjung Putting, Central Borneo. Int J Primatol 9:1-35.

Goodall J. 1970. Tool-using in primates and other vertebrates. Adv Study Behav 3:195-249.

Lazenby RA, Skinner MM, Hublin J-J, Boesch C. 2011. Metacarpal trabecular architecture variation in the chimpanzee (Pan troglodytes): evidence for locomotion and tool-use? Am J Phys Anthropol 144:215-225.

Lesnik J. 2011a. Tools and termites: implications for the foraging behavior of the Swartkrans hominids. Ann Arbor, MI: University of Michigan.

Lesnik J. 2011b. Bone tool texture analysis and the role of termites in the hominid diet. Paleoanthropology 2011:268281.

Lesnik J. 2014. Termites in the hominin diet: a meta-analysis of termite genera, species and castes as a dietary supplement for South African robust australopithecines. J Hum Evol 71: 94-104.

Lovejoy CO, Simpson SW, White TD, Asfaw B, Suwa G. 2009. Carfeful climbing in the Miocene: The forelimbs of Ardipithecus ramidus and humans are primitive. Science 326:70.

Marzke M, Pouydebat E, Laurin M, Gorce P, Bels V. 2009. A clarification of Pouydebat et al., 2008, evolution of grasping among anthropoids. J Evol Biol 22: 2554-2557.

Marzke M, Wullstein K. 1996. Chimpanzee and human grips: a new classification with a focus on evolutionary morphology. Int J Primatol 17:117-139.

McGrew WC, Tutin CEG, Baldwin PJ. 1979. Chimpanzees, tools, and termites: cross-cultural comparisons of Senegal, Tanzania, and Rio Muni. Man 14:185-214.

Meulman EJM, Sanz CM, Visalberghi E, van Schaik, CP. 2012. The role of terrestriality in promoting primate technology. Evol Anthropol 21:58-68.

Morris D. 1963. Biology of art: a study of picture-making behaviour of the great apes and its relationship to human art. London: Methuen.

Napier J. 1956. The prehensile movement of the human hand. J Bone Joint Surg B 38:902-913.

Napier J. 1960. Studies of the hands of living primates. Proc Zool Soc Lond 134:647-657.

Napier J. 1962. Fossil hand bones from Olduvai Gorge. Nature 96:409-411.

Pouydebat E, Laurin M, Gorce P, Bels V. 2008. Evolution of grasping among anthropoids. J Evol Biol 21:1732-1743.

Preuschoft H. 1973. Functional anatomy of the upper extremity. In: Bourne G, editor. The chimpanzee. New York: KargerVerlag. p 34-120.

Sabater Pi J. 1974. An elementary industry of the chimpanzees in the Okorobiko Mountains, Rio Muni (Republic of Equatorial Guinea), West Africa. Primates 15:351-364.

Sanz C, Deblauwe I, Tagg N, Morgan DB. 2014. Insect prey characteristics affecting regional variation in chimpanzee tool use. J Hum Evol 71:28-37. 
Sanz C, Morgan D. 2007. Chimpanzee tool technology in the Goualougo Triangle, Republic of Congo. J Hum Evol 52:420433

Sanz C, Morgan D, Gulick S. 2004. New insights into chimpanzees, tools, and termites from the Congo Basin. Am Nat 164: 567-581.

Schick K, Toth N, Garufi G. 1999. Continuing investigation into the stone tool-making and tool-using capabilities of a bonobo (Pan paniscus). J Archaeol Sci 26:821-832.

Selin A. 2003. Pencil grip. A descriptive model and four empirical studies. Abo: Abo Akademi University.

Toth N, Schick K, Savage-Rumbaugh ES, Sevcik RA, Rumbaugh SM. 1993. Pan the tool-maker: investigations into the stone tool-making and tool-using capabilities of a bonobo (Pan paniscus). J Archaeol Sci 20:81-91.

Tutin CE, Fernandez M. 1983. Gorillas feeding on termites in Gabon, West Africa. J Mammal 64:530-531.

Tuttle RH. 1969a. Knuckle-walking and the problem of human origins. Science 166:953-961.

Tuttle RH. 1969b. Quantitative and functional studies on the hands of the Anthropoidea. I. The Hominoidea. J Morphol 128:309-364.

Wynn T, Hernandez-Aguilar RA, Marchant LF, McGrew WC. 2011. "An ape's view of the Oldowan" revisited. Evol Anthropol 20:181-197.

Wynn T, McGrew WC. 1989. An ape's view of the Oldowan. Man 24:283-298. 